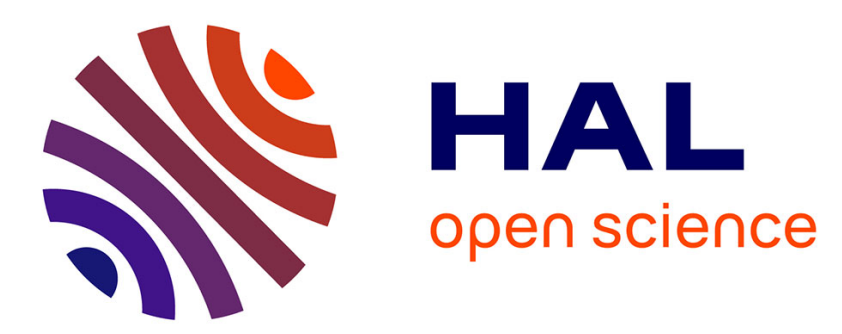

\title{
Late-onset agoraphobia: general population incidence and evidence for a clinical subtype.
}

Karen Ritchie, Joanna Norton, Anthony Mann, Isabelle Carrière, Marie-Laure Ancelin

\section{- To cite this version:}

Karen Ritchie, Joanna Norton, Anthony Mann, Isabelle Carrière, Marie-Laure Ancelin. Late-onset agoraphobia: general population incidence and evidence for a clinical subtype.. The American Journal of Psychiatry, 2013, 170 (7), pp.790-8. 10.1176/appi.ajp.2013.12091235 . inserm-00908016

\section{HAL Id: inserm-00908016 https://www.hal.inserm.fr/inserm-00908016}

Submitted on 30 Jun 2014

HAL is a multi-disciplinary open access archive for the deposit and dissemination of scientific research documents, whether they are published or not. The documents may come from teaching and research institutions in France or abroad, or from public or private research centers.
L'archive ouverte pluridisciplinaire HAL, est destinée au dépôt et à la diffusion de documents scientifiques de niveau recherche, publiés ou non, émanant des établissements d'enseignement et de recherche français ou étrangers, des laboratoires publics ou privés. 
Word count: abstract 249; text 3459; all manuscript 5948

Tables: 2 References: 36

\section{Late-onset agoraphobia: general population incidence and evidence for a clinical sub-type}

Karen Ritchie $\mathrm{PhD}^{123^{*}}$, Joanna Norton $\mathrm{PhD}^{12^{*}}$, Anthony Mann $\mathrm{MD}^{4}$, Isabelle Carrière $\mathrm{PhD}^{12}$, Marie-Laure Ancelin $\mathrm{PhD}^{12}$

*Joint first authors

${ }^{1}$ Inserm, U1061, Montpellier, France;

${ }^{2}$ University of Montpellier 1, Montpellier, France;

${ }^{3}$ Faculty of Medicine, Imperial College, London, United Kingdom;

${ }^{1}$ Institute of Psychiatry, King's College, London, United Kingdom

\section{Corresponding Author}

Karen Ritchie

Inserm U1061, Neuropsychiatry: Epidemiological and Clinical Research,

La Colombière Hospital,

34093 Montpellier cedex 5, France

Tel: +334996145 68; Fax: +33499614579

Email: karen.ritchie@inserm.fr

Keywords: agoraphobia, anxiety, depression, suicidal ideation, elderly, longitudinal study 


\section{ABSTRACT}

Objective. To estimate general population incidence of late-life agoraphobia, its clinical characteristics and risk factors.

Methods. 1968 persons aged 65 and above were randomly recruited from the electoral rolls of the district of Montpellier, France. Prevalent and incident agoraphobia diagnosed by a standardized psychiatric examination and validated by a clinical panel was assessed at base-line and over 4 year follow-up.

Results. The one-month prevalence of agoraphobia was estimated at $10.4 \%$ of whom $10.9 \%$ reported having the first episode at age 65 or over. During the 4 -year follow-up $11.2 \%$ of participants without agoraphobia at base-line were classified as cases giving an incident rate of 32 per 1000 person years. These 132 incident late-onset cases were associated with higher incident rates of anxiety disorders and suicidal ideation. Only two incident cases had past or concurrent panic attacks, which was not significantly different from non-cases. The principal base-line risk factors for incident cases derived from a multivariate model incorporating all significant risk factors were younger age of onset (OR=0.94; $95 \% \mathrm{Cl} 0.90-0.99, \mathrm{p}=0.02)$, poorer visuospatial memory performance $(\mathrm{OR}=1.60 ; 95 \% \mathrm{Cl}$ 1.02-2.49, $\mathrm{p}=0.04)$, severe depression $(\mathrm{OR}=2.62 ; 95 \% \mathrm{Cl} 1.34-5.10, \mathrm{p}=0.005)$ and trait anxiety (OR=1.73; 95\% $\mathrm{Cl} 1.03-2.90, \mathrm{p}=0.04$ ). No significant association was found with cardiac pathologies.

Conclusion. Agoraphobia has high prevalence in the elderly and unlike younger cases, late-onset cases are not more common in women, and are not associated with panic attacks, suggesting a latelife sub-type. Severe depression, trait anxiety and poor visuospatial memory are the principal risk factors for late-onset agoraphobia. 


\section{INTRODUCTION}

Increasing interest is now being shown in phobias in the elderly as they have been associated with higher mortality, increased proinflammatory cytokines ${ }^{1,2}$ and stress reactivity ${ }^{3}$, lower heart rate variability, ${ }^{4}$ fatal coronary artery disease, and sudden cardiac death ${ }^{5}$. Recent studies of anxiety disorders in the elderly suggest that rates of all phobias may not only be much higher than previous epidemiological studies have suggested, but perhaps even constitute the most common form of anxiety disorder in this population ${ }^{6}$. Agoraphobia is a specific form of phobia which has been differentiated from other phobias within the international classifications of psychiatric disorder, principally due to its assumed association with panic attacks. It is defined as a fear and avoidance of being in places or situations from which escape might be difficult in the event of sudden incapacitation. As a result of such fears, the agoraphobic person avoids travel or requires a companion when away from home. Moderate cases may cause some constriction in lifestyle, while severe cases of agoraphobia may result in the person being completely housebound or unable to leave home unaccompanied. Within DSM-IV ${ }^{7}$ agoraphobia is a sub-section of panic disorder. Agoraphobia without a history of panic disorder may be classified as such, but is considered atypical. Agoraphobia in the elderly has received little attention, being considered to be principally a disorder of young adulthood ${ }^{2}$; the Epidemiological Catchment Area study in the U.S. for example reported a one month prevalence of agoraphobia in persons over 65 of under $1.4 \%^{8}$. Clinical reports have suggested, however, that this form of phobia is commonly overlooked in the elderly; unwillingness to go outside the home being easily attributed to poor health and loss of social networks ${ }^{9}$. Undetected agoraphobia in the elderly is highly unlikely to improve spontaneously ${ }^{10}$ and given its association with anxiety and depressive symptoms, is likely to lead to a downward spiral of loneliness and 
deteriorating mental health. On the other hand, treatment of agoraphobia with cognitive-

behavioural therapies and psychotropics has been proven to be highly successful at all ages ${ }^{9,11,12}$.

The aim of the present study is to provide estimates of the rates, clinical characteristics and risk factors for late-onset agoraphobia from a large prospective population study; previous studies being compromised by small samples, hierarchical case-finding procedures excluding cases with comorbidity, and failure to take into account potential confounding factors. The current study is part of a longitudinal project (the ESPRIT study) examining psychiatric disorder in the elderly using a standardized clinical interview based on international diagnostic algorithms for agoraphobia with clinical case validation. The study also has extensive information relating to clinical and life-style variables, permitting the identification of risk factors, and adjustment for multiple potential confounding factors.

\section{METHOD}

\section{Sample}

Community dwelling persons 65 years and over, were recruited by random selection from the fifteen electoral rolls of the Montpellier district between March 1999 and February 2001 as part of the ESPRIT study of late-life psychiatric disorder ${ }^{13}$. Of the persons contacted $72.7 \%$ accepted. Refusers were replaced by another subject drawn at random from the same electoral division such that each division is equally represented. Subjects refusing were slightly older and more likely to live alone than non-refusers. Participants were given a base-line examination and re-examined with a detailed psychiatric interview on two further occasions at intervals of two and four years. Seventy persons diagnosed with dementia at base-line were excluded from the present study. Dementia was diagnosed by a neurologist as part of a standardized examination (see below) and validated by a panel of independent neurologists. Of the 2189 dementia-free participants included in the ESPRIT 
study, 221 were excluded because of missing data on agoraphobia or on one of the main sociodemographic variables at baseline. The cross-sectional analyses were thus conducted on a maximum of 1968 persons. Participants did not differ from those excluded from the analysis for baseline sociodemographic and health variables. The longitudinal analysis was carried out on participants with either 2-year or 4-year follow-up examinations. Of the baseline sample, 98 participants (5\%) were missing both follow-up examinations, (38 died, 26 were lost to follow-up and 34 refused to participate). Compared to the follow-up participants, those lost to follow-up were older $(p=0.0004)$, with a lower educational level $(p=0.02)$, with more frequent baseline respiratory problems $(p<0.0001)$, cardio and cerebro-vascular pathologies $(p=0.02)$, and disability $(p<0.0001)$. There were no significant differences for baseline depressive symptomatology, anxiety or agoraphobia. Incident cases of dementia $(n=48)$ were retained in the study as they were still community-dwelling and able to undertake the examinations. In cases of doubt family proxies and general practitioners were consulted. The study protocol was approved by the Ethics Committee of the University-Hospital of Kremlin-Bicêtre and written informed consent was obtained from each participant.

\section{Measures}

Participants were required to attend a half-day examination by a neurologist and a centre interviewer (nurse or psychologist) at the Gui de Chauliac Neurology Hospital (Montpellier, France). Persons unable to come to the study centre ( $7 \%$ of participants) were examined in their homes. The following procedures were carried out:

A standardized health interview covering present and past health and medication use (subjects were asked to bring medications to the centre). The examination covered past and current vascular disease (angina pectoris, arrhythmia, lower limb arteritis, heart failure, myocardial infarction, cardiovascular surgery, stroke) and other chronic illnesses (cancer, osteoporosis, asthma, diabetes defined as fasting glucose $\geq 7 \mathrm{mmol} / \mathrm{l}$ or treatment, hypercholesterolemia defined as total cholesterol 
$\geq 6.2 \mathrm{mmol} / \mathrm{l}$ or treatment, hypertension defined as resting blood pressure $\geq 160 / 95 \mathrm{~mm} \mathrm{Hg}$ or treatment, and thyroid disorders).

Confinement (to bed, home or neighbourhood) for health reasons was noted and disability measured using the Rosow and Breslow mobility scale (ability to do heavy housework, walk over 500 metres and go up and down two flights of stairs) ${ }^{14}$ and the Lawton Instrumental Activities of Daily Living scale $^{15}$. Recent exposure to adverse life events in the past year was assessed at base-line using the Gospel Oak Questionnaire ${ }^{16}$.

A standardized clinical examination based on ICD-10 criteria ${ }^{17}$ to detect neurological and cardiovascular disorder, including measures of sitting and standing blood pressure, was carried out at base-line and at each follow-up examination by a research neurologist.

A standardized psychiatric interview, the Mini International Neuropsychiatric Interview (MINI) (French version 5.00) previously validated within the general population setting ${ }^{18}$ recorded life-time and current DSM-IV ${ }^{7}$ Axis I psychiatric disorders and suicidal ideation. Interviewers were trained for three months within the Department of Adult Psychiatry of the La Colombière Psychiatric Hospital, and positive cases were reviewed by a panel of psychiatrists, notably to distinguish agoraphobia from specific and social phobias. The psychiatrists reviewed cases independently in accordance with DSMIV criteria by reference to all information provided by the MINI examination, participant responses as recorded by the interviewers, all other biological and clinical data available for the subject and if necessary after consultation with the general practitioner. Consensus agreement was subsequently reached on all cases. Only one case was reclassified as a non-case of agoraphobia (specific phobia). The MINI uses a non-hierarchical case-identification procedure thus permitting the diagnosis of psychiatric co-pathologies. The Center for Epidemiologic Studies-Depression Scale (CES-D) ${ }^{19}$ was used to detect levels of current depressive symptomatology. Depression was classified as 'Severe' (current Major Depressive Episode by the MINI or a CES-D score>23), 'Mild' (CES-D score 
between 16 and 22) or 'None' (CES-D score lower than 16) ${ }^{20}$. Trait anxiety was assessed with the Spielberger scale ${ }^{21}$. Scores in the highest tertile were compared to the lower two.

Cognitive functioning. Visuospatial memory and semantic access (verbal fluency) were assessed respectively by the Benton Visual Retention Test ${ }^{22}$ and the Isaacs' Set Test ${ }^{23}$. Scores were grouped into tertiles and the lowest compared to the highest two.

Childhood environment $\mathrm{A}$ retrospective self report questionnaire ${ }^{24}$ examining traumatic experiences during childhood and adolescence and covering 25 adverse and 8 protective factors, was given to subjects for completion at the second follow-up.

\section{Statistical Analysis}

A sensitivity analysis was conducted to compare participants with those excluded using the $\mathrm{Chi}^{2}$ test. The $\mathrm{Chi}^{2}$ test and Fisher exact test were used to compare crude rates for psychiatric co-morbidities at baseline and follow-up. The clinical characteristics of the sample of 1968 subjects is described according to presence or not of agoraphobia at baseline, giving p-values from a logistic regression analysis adjusted for age, sex and education. The incident rate over the follow-up was calculated on 1175 subjects with no baseline history of agoraphobia and data available at both follow-ups. For new cases the exact date of onset during the follow-up period was not available, onset was therefore considered to have occurred midway between the two examinations. Population incidence was estimated by dividing the number of new cases occurring during follow-up by the total number of agoraphobia-free years lived by the cohort from base-line, expressed as number of new cases per 1000 person-years. Longitudinal associations between baseline socio-demographic, health and lifestyle variables and incident agoraphobia were examined using a mixed logistic model ${ }^{25}$ (SAS version 9.2 NLMIXED procedure), taking into account the correlation between within-subject responses (repeated evaluations). This model allows the inclusion of subjects with incomplete 
responses across time. The analysis of new onset cases (excluding recurrent cases) was thus conducted on a maximum of 1461 subjects (1376 with 2-year follow-up data and 1260 with 4-year follow-up data) with neither past nor current agoraphobia at baseline, and at least one follow-up examination with complete data on agoraphobia and its principal covariates. Variables with a p-value $<0.15$ in the univariate model were entered into a final multivariate model. A Cox's proportional hazards model was used to examine the association between base-line agoraphobia and incident cardio-vascular events.

\section{RESULTS}

In our population of community-dwelling adults 65 years and over, the base-line one-month prevalence of agoraphobia is observed to be $10.4 \%$, with a life-time prevalence of $17.7 \%$. Of these, $10.9 \%$ of cases were reported as having their onset over age 65 . The sample, overall and according to baseline agoraphobia, is described in Table 1. Agoraphobia is more frequent in women ( $p<0.0001)$ and in lower educational levels ( $p=0.01)$. The mean (SD) age of cases is $72.3(5.2)$ and for non-cases 72.8 (4.9) (non significant). Regarding other psychiatric conditions, agoraphobia is significantly associated with trait anxiety $(p=0.0005)$, severe depressive symptomatology $(p<0.0001)$ and a history of major depression $(p=0.02)$.

Table 1 here

Over the four-year follow-up 11.2\% (132/1175) of the sample had a first episode of agoraphobia. The incidence rate is estimated at 32 per 1000 person-years. During the follow-up period these subjects also had more frequent first episodes of other anxiety disorders (11.5\% in cases vs. $5.0 \%$ in noncases; $\left.\mathrm{Chi}^{2}=7.96 ; \mathrm{p}=0.005\right)$, specifically general anxiety disorder ( $8.5 \%$ in cases vs. $4.5 \%$ in non-cases; $\left.\mathrm{Chi}^{2}=3.43 ; \mathrm{p}=0.06\right)$, and marginally more frequent suicidal ideation $(13.3 \%$ in cases vs. $8.3 \%$ in noncases; $\left.\mathrm{Chi}^{2}=3.06 ; \mathrm{p}=0.08\right)$. There was no increase compared to non-agoraphobic subjects in the incidence of severe depression ( $6.5 \%$ in cases vs. $4.3 \%$ in non-cases; Fisher exact test $F=0.11 ; p=0.29$ ). Only one new case of agoraphobia (0.8\%) had panic disorder within the follow-up period and one 
reported previous panic disorder at baseline (0.8\%). These rates were not significantly different to those found among non-cases.

In order to determine potential risk factors for agoraphobia onset in the elderly, a mixed regression model adjusted for age and time to diagnosis examined the association between socio-demographic and clinical characteristics at base-line and incident cases of agoraphobia at 2 and 4 year follow-up (Table 2). The model showed a significant effect of age, with the odds of incident agoraphobia decreasing with age $(\mathrm{OR}=0.95 ; 95 \% \mathrm{Cl} 0.91-0.98 ; \mathrm{p}=0.02)$. There was no significant effect of time and no interaction between time and age. A significant sex difference was not found in these late-onset cases. Incident agoraphobia was associated with severe baseline depression (OR=3.81; $95 \% \mathrm{Cl} 2.08$ 6.97; $p<0.0001)$, a history of major depression (OR=1.70 95\% $\mathrm{Cl} 1.05-2.74 ; p=0.03)$, lower scores on the Benton visual recall test $(\mathrm{OR}=1.53 ; 95 \% \mathrm{Cl} 0.98-2.39, \mathrm{p}=0.058)$, and a higher score on the Spielberger trait anxiety scale $(\mathrm{OR}=2.48 ; 95 \% \mathrm{Cl}$ 1.58-3.90, $\mathrm{p}<0.0001)$. New cases of agoraphobia had higher rates of mobility restriction (heavy housework; ability to climb stairs; walking more than 500 metres) $(\mathrm{OR}=2.33 ; 95 \% \mathrm{Cl} 1.43-3.81 ; \mathrm{p}<0.001)$ but not increased rates of confinement due to poor health or difficulty with instrumental activities of daily living (IADLs). Incident agoraphobia was not associated with base-line cardiovascular disease. A Cox model was also used to examine the relationship between base-line agoraphobia and incident cardiovascular disease adjusted for age, sex and education. This was also found to be non-significant ( $H R=1.07 ; 95 \% \mathrm{Cl} 0.53-2.14, p=0.85)$.

Table 2 here

A multivariate model was used to determine the most significant predictors of new cases, taking into account age, sex and all the risk factors identified above. This model retained age $(\mathrm{OR}=0.94 ; 95 \% \mathrm{Cl}$ 0.90-0.99, $p=0.018$ ), Benton visual recall test performance (OR=1.60; 95\% $\mathrm{Cl} 1.02-2.49, \mathrm{p}=0.04)$, severe current depression $(\mathrm{OR}=2.62 ; 95 \% \mathrm{Cl} 1.34-5.10, \mathrm{p}=0.005)$ and Spielberger trait anxiety $(\mathrm{OR}=1.73 ; 95 \% \mathrm{Cl} 1.03-2.90, \mathrm{p}=0.04)$ as significant predictors of incident agoraphobia. While base-line 
severe depression greatly increased odds of subsequent agoraphobia, incident cases were not accompanied by the onset of new episodes of severe depression.

\section{DISCUSSION}

\section{Prevalence, incidence and co-morbidity}

Our prospective study of agoraphobia in a large general population cohort using a standardized clinical interview based on DSM-IV criteria with clinical validation of cases, suggests the disorder to have a much higher prevalence in the elderly than was suggested by the 1988 ECA study (10.4\% versus $1.4 \%)$. A subsequent study carried out in the U.K. using DSM III criteria ${ }^{26}$ on a small sample of 168 elderly persons from a community care service found similarly high rates of agoraphobia (14.9\%), which was lowered to $6.5 \%$ when hierarchical exclusion rules were applied. The exclusion rule includes co-morbid major depression, which if applied to our cohort would have more than halved the base-line prevalence estimate.

Over the four-year follow-up period we detected and validated 132 new cases of agoraphobia (11.2\% of the base-line population) without application of hierarchical decision rules, giving an estimated general population incidence of 32 per 1000 person-years. During follow-up these new cases were also seen to be associated with incidence of other anxiety disorders (principally generalized anxiety disorder) and suicidal ideation. Although agoraphobia was seen to be commonly preceded by depression, new cases of agoraphobia were not accompanied by incident depression, suggesting that depression is a risk factor, and not a consequence of agoraphobia.

The overall rates observed for panic disorder (less than 1\%) are similar to those found by the National Co-morbidity Survey Replication ${ }^{27}$. The importance of panic attacks as a risk factor for agoraphobia in younger populations ${ }^{28,29}$ has led to an assumption that they are part of the same syndrome, largely based on the behavioral hypothesis that agoraphobia is a conditioned avoidance 
response to the aversive stimulus of spontaneous panic attacks. According to this model panic attacks are the primary diagnosis, although other investigators including the behavioral scientist Marks $^{30}$, have questioned the temporal precedence and causal role of panic attacks in the development of agoraphobia. Clinical studies have suggested that late onset cases of agoraphobia in particular may be characterized by high rates of past major depression rather than panic attacks ${ }^{9}$ although this has never been investigated in a prospective epidemiological study. Our findings support this observation, with only two of the 132 incident cases having a previous or recent episode of panic attacks, but having more than doubled the rates of depression found in non-agoraphobic persons at base-line. Overall, results from the current study largely support Flint's ${ }^{9}$ observation that depression is the primary co-pathology and that antidepressants and/or behavioral therapies, rather than benzodiazepines, should be the treatment of choice in elderly cases of agoraphobia. At baseline we found that only $6 \%$ of persons with agoraphobia were treated with an anti-depressant and $13 \%$ with an anxiolytic (results not shown). These rates were not significantly higher than for the non-agoraphobic group.

\section{Risk factors}

The principal documented risk factors for all phobias are younger age, female gender, living alone, physical illness, other anxiety disorders and depression, not having been raised by both parents, and cognitive disorder ${ }^{31-34}$. All of these risk factors were examined in the present study. The odds of incident agoraphobia during follow-up were seen to decrease with age at baseline, whereas poorer visuospatial memory, high trait anxiety and severe depression at baseline were associated with increased odds. On the other hand we found no significant association with living alone, physical illness, or child-rearing conditions (data not shown). Interestingly, although a higher prevalence rate of agoraphobia was observed in women at base-line, the slightly greater number of women in new cases aged 65 and above did not quite reach significance, and disappeared in the multivariate risk model, probably due to confounding by depression and anxiety. 
Boldrini et al. ${ }^{35}$ found agoraphobia to be specifically associated with spatial learning impairment and our findings further support this observation, with agoraphobia onset being accompanied by poor performance on a visuospatial memory task but not a verbal fluency test. Poor visuospatial performance has been associated with falls and sensory impairment, which might have confounded the association, however, no association was found with either sensory impairment or falls.

It has previously been suggested ${ }^{36}$ that a past history of any anxiety disorder doubles the probability of both suicidal ideation and suicide attempts. We observed higher rates of suicidal ideation in persons with agoraphobia at baseline (16.6\% vs. $9.1 \%$ for non-cases). This observation was further confirmed prospectively, with new cases of agoraphobia being paralleled by an increase in the incidence of suicidal ideation. On the other hand, no association was found between onset of agoraphobia and base-line cardiac pathology. Nor were new cases accompanied by an increase in incidence of cardiac disorder in contrast to previous observations relating to phobic anxiety in general $^{5,4}$. Persons with reduced mobility were also found to be at greater risk, however, its significance disappears within a multivariate analysis taking into account competing risk factors.

A weakness of the study has been reliance on retrospective recall by participants of life events and previous episodes of agoraphobia. While the refusal rate is low for an epidemiological study we cannot exclude bias due to loss at both base-line and follow-up of a more disabled group, which along with our non-inclusion of institutionalized persons at base-line may have led to an underestimation of the actual number of cases. Depression and poor physical health are strongly associated in the elderly, and while we have eliminated confounding due to all the main causes of chronic and acute illness in this cohort we have not examined self-perceived health which may have had an independent effect. Furthermore, while we have demonstrated the significance of depression as a risk factor, the study design does not permit us to clarify the causal association between the two. Further research is required to clarify whether there may be a direct relationship based on 
underlying neurophysiological changes driven by chronic depressive symptomatology or whether the association is further moderated by complex interactions implicating genetic and biochemical vulnerability, social learning and cognitive processes. On the other hand the study has a number of strengths; incident case identification procedures have been rigorous and this well phenotyped study has been able to examine a large number of potential confounding factors within a prospective design. Overall our findings suggest that agoraphobia may be relatively common in the elderly, occurring in over $10 \%$ of community-dwelling persons. Late-onset cases show some clear distinctions from clinical reports of early onset cases. Firstly there seems to be no clear sex difference. While early onset cases have been more frequently associated with panic disorder, this appears not to be the case in late-onset cases, in which severe depression is predominant as a risk factor rather than a consequence of the disorder. The principal risk factors for late-onset agoraphobia are younger age, severe depression, trait anxiety and poor performance on a test of visuospatial memory. Unlike other phobias, there does not appear to be increased risk for cardiac pathology, although our four-year follow-up period may be too short to definitively conclude on this point. Agoraphobia in this cohort is clearly under-treated, with preference still being for anxiolytics rather than anti-depressants despite the presence of severe depressive symptoms. Screening for agoraphobia in the elderly is clearly worthwhile as it is a highly treatable condition which may be masked by depression, and overlooked due to lack of history of panic attacks. Its association in the elderly with suicidal ideation is of clinical concern, as persons with agoraphobia may be less likely to seek assistance. Our finding that agoraphobia in the elderly has a clinically atypical presentation in comparison with younger cases is also of relevance to the on-going process of revision of diagnostic criteria for psychiatric disorder, suggesting the need to consider the possibility of a syndrome sub-type in older populations.

\section{Clinical Vignette}

A 76 year-old married woman reported experiencing a depressive episode 10 years prior to interview following a traumatic event. At this time she received only symptomatic treatment for sleeping 
difficulties. She has subsequently experienced chronic depressive symptoms, notably periods of tearfulness and sleep disturbance but did not have major depressive disorder at the time of examination. She currently reports being unable to go out alone for fear of something happening to her, and is particularly fearful of empty streets, crowds and public transport. She is able to drive but will only do so if accompanied. She has no past history of panic disorder and no chronic or acute illnesses or disability. Her self-rated health is very good. At two year follow-up her fears had worsened and she rarely leaves the house as her husband is now disabled.

Funding/ Support: The Esprit Study has been funded by an unconditional grant from Novartis and from the National Research Agency (ANR Project 07 LVIE004).

Declaration of Conflict of Interest: The authors have none to declare

\author{
References
}

1 Covelli V, Maffione AB, Nacci C, Tato E, Jirillo E. Stress, neuropsychiatric disorders and immunological effects exerted by benzodiazepines. Immunopharmacol Immunotoxicol 1998; 20: 199-209.

2 Luchins DJ, Rose RP. Late-life onset of panic disorder with agoraphobia in three patients. Am J Psychiatry 1989; 146: 920-1.

3 Chaudieu I, Beluche I, Norton J, Boulenger JP, Ritchie K, Ancelin ML. Abnormal reactions to environmental stress in elderly persons with anxiety disorders: Evidence from a population study of diurnal cortisol changes. Journal of Affective Disorders 2007; in press.

$4 \quad$ Kawachi I, Sparrow D, Vokonas PS, Weiss ST. Decreased heart rate variability in men with phobic anxiety (data from the Normative Aging Study). Am J Cardiol 1995; 75: 882-5.

5 Albert CM, Chae CU, Rexrode KM, Manson JE, Kawachi I. Phobic anxiety and risk of coronary heart disease and sudden cardiac death among women. Circulation 2005; 111: 480-7.

6 Bryant C, Jackson $\mathrm{H}$, Ames $\mathrm{D}$. The prevalence of anxiety in older adults: methodological issues and a review of the literature. J Affect Disord 2008; 109: 233-50.

7 American P, Association. Diagnostic and Statistical Manual of Mental Disorders. Washington: American Psychiatric Association, 2000.

8 Regier DA, Boyd JH, Burke JD, Jr., Rae DS, Myers JK, Kramer M, Robins LN, George LK, Karno M, Locke BZ. One-month prevalence of mental disorders in the United States. Based on five Epidemiologic Catchment Area sites. Arch Gen Psychiatry 1988; 45: 977-86. 
9 Flint AJ. Epidemiology and comorbidity of anxiety disorders in later life: implications for treatment. Clin Neurosci 1997; 4: 31-6.

10 Wittchen $\mathrm{H}$ Natural course and spontaneous remissions of untreated anxiety disorders. Berlin: Springer Verlag, 1986.

11 Hendriks GJ, Keijsers GP, Kampman M, Hoogduin CA, Oude Voshaar RC. Predictors of outcome of pharmacological and psychological treatment of late-life panic disorder with agoraphobia. Int J Geriatr Psychiatry 2012; 27: 146-50.

12 Hendriks GJ, Keijsers GP, Kampman M, Oude Voshaar RC, Verbraak MJ, Broekman TG, Hoogduin CA. A randomized controlled study of paroxetine and cognitive-behavioural therapy for late-life panic disorder. Acta Psychiatr Scand 2010; 122: 11-9. Prevalence of DSM-IV psychiatric disorder in the French elderly population. Br J Psychiatry 2004; 184: 147-52.

14 Rosow I, Breslau N. A Guttman health scale for the aged. J Gerontol 1966; 21: 556-9.

15 Lawton MP. Scales to measure competence in everyday activities. Psychopharmacol Bull 1988; 24: 609-14.

16 Harwood RH, Prince MJ, Mann AH, Ebrahim S. The prevalence of diagnoses, impairments, disabilities and handicaps in a population of elderly people living in a defined geographical area: the Gospel Oak project. Age Ageing 1998; 27: 707-14.

17 WHO International Classification of Diseases. Tenth Revision. Geneva: WHO, 1992.

18 American Psychiatric Association Diagnostic and Statistical Manual of Mental Disorders (DSM-IV). Washington, DC: American Psychiatric Association, 1994.

19 Radloff L. The CES-D scale: a self-report depression scale for research in the general population. Appl Psychol Measurement 1977; 1: 385-401.

20 Ryan J, Carriere I, Ritchie K, Stewart R, Toulemonde G, Dartigues JF, Tzourio C, Ancelin ML. Late-life depression and mortality: influence of gender and antidepressant use. $\mathrm{Br} \mathrm{J}$ Psychiatry 2008; 192: 12-8.

21 Spielberger C Manual for the State-Trait Anxiety Inventory. Palo Alto: Consulting Psychologists Press, 1983.

22 Benton A Manuel pour l'application du test de rétention visuelle. Applications cliniques et expérimentales. Paris: Centre de Psychologie Appliquée, 1965.

23 Isaacs B, Kennie A. The Set test as an aid to the detection of dementia in old people. $\mathrm{Br} J$ Psychiatry 1973; 123: 467-70.

24 Ritchie K, Jaussent I, Stewart R, Dupuy AM, Courtet P, Ancelin ML, Malafosse A. Association of adverse childhood environment and 5-HTTLPR Genotype with late-life depression. J Clin Psychiatry 2009; 70: 1281-8.

25 Carriere I, Bouyer J. Choosing marginal or random-effects models for longitudinal binary responses: application to self-reported disability among older persons. BMC Med Res Methodol 2002; 2: 15.

26 Lindesay J, Bannerjee S. Phobic disorders in the elderly: a comparison of three diagnostic systems. International Journal of Geriatric Psychiatry 1993; 8: 387-93.

27 Byers AL, Yaffe K, Covinsky KE, Friedman MB, Bruce ML. High occurrence of mood and anxiety disorders among older adults: The National Comorbidity Survey Replication. Arch Gen Psychiatry 2010; 67: 489-96.

28 Eaton WW, Kessler RC, Wittchen HU, Magee WJ. Panic and panic disorder in the United States. Am J Psychiatry 1994; 151: 413-20.

29 Weiller E, Bisserbe JC, Boyer P, Lepine JP, Lecrubier Y. Social phobia in general health care: an unrecognised undertreated disabling disorder. Br J Psychiatry 1996; 168: 169-74.

$30 \quad$ Marks IM Phobias and Rituals. New York: Oxford University Press, 1978.

31 Schaub RT, Linden M. Anxiety and anxiety disorders in the old and very old--results from the Berlin Aging Study (BASE). Compr Psychiatry 2000; 41: 48-54. 
32 van Balkom AJ, Beekman AT, de Beurs E, Deeg DJ, van Dyck R, van Tilburg W. Comorbidity of the anxiety disorders in a community-based older population in The Netherlands. Acta Psychiatr Scand 2000; 101: 37-45.

33 Schulz S, Moser D, Bishop J. Phobic anxiety in late-life in relationship to cognition and 5HTTLPR polymorphism. Psychiatr Genet 2005; 14: 305-6.

34 Cohen $\mathrm{Cl}$, Magai C, Yaffee R, Huangthaisong P, Walcott-Brown L. The prevalence of phobia and its associated factors in a multiracial aging urban population. Am J Geriatr Psychiatry 2006; 14: 507-14.

35 Boldrini M, Del Pace L, Placidi GP, Keilp J, Ellis SP, Signori S, Placidi GF, Cappa SF. Selective cognitive deficits in obsessive-compulsive disorder compared to panic disorder with agoraphobia. Acta Psychiatr Scand 2005; 111: 150-8.

36 Sareen J, Cox BJ, Afifi TO, de Graaf R, Asmundson GJ, ten Have M, Stein MB. Anxiety disorders and risk for suicidal ideation and suicide attempts: a population-based longitudinal study of adults. Arch Gen Psychiatry 2005; 62: 1249-57. 
Table 1. Baseline association between health and lifestyle variables and agoraphobia (adjusted for age, sex and education)

\begin{tabular}{|c|c|c|c|c|c|}
\hline \multirow[b]{2}{*}{ Variable } & \multirow[b]{2}{*}{ Class } & \multicolumn{4}{|c|}{ Agoraphobia } \\
\hline & & $\begin{array}{c}\text { Total } \\
\% \\
(1968)\end{array}$ & $\begin{array}{c}\text { No } \\
\% \\
(1764)\end{array}$ & $\begin{array}{c}Y e s \\
\% \\
(204)\end{array}$ & $p$-value \\
\hline \multirow[t]{5}{*}{ Age } & $65-69$ & 31.66 & 31.52 & 32.84 & \\
\hline & 70-74 & 35.37 & 34.81 & 40.20 & \\
\hline & $75-79$ & 21.34 & 21.77 & 17.65 & \\
\hline & $80+$ & 11.64 & 11.90 & 9.31 & 0.22 \\
\hline & & $(1968)$ & $(1764)$ & $(204)$ & \\
\hline \multirow[t]{3}{*}{ Sex } & Male & 41.77 & 43.65 & 25.49 & - \\
\hline & Female & 58.23 & 56.35 & 74.51 & $<0.0001$ \\
\hline & & $(1968)$ & $(1764)$ & $(204)$ & \\
\hline \multirow[t]{4}{*}{ Education } & Low & 23.63 & 23.19 & 27.45 & \\
\hline & Average & 29.17 & 28.23 & 37.25 & \\
\hline & High & 47.21 & 48.58 & 35.29 & 0.011 \\
\hline & & $(1968)$ & $(1764)$ & $(204)$ & \\
\hline \multirow[t]{4}{*}{ BMI $\left(\mathrm{kg} / \mathrm{m}^{2}\right)$} & $<25$ & 53.79 & 53.49 & 56.37 & - \\
\hline & $25-29$ & 37.91 & 38.16 & 35.78 & \\
\hline & $\geq 30$ & 8.30 & 8.35 & 7.84 & 0.84 \\
\hline & & $(1952)$ & $(1748)$ & $(204)$ & \\
\hline Regular use of anti-inflammatory & No & 87.74 & 87.40 & 90.69 & - \\
\hline \multirow[t]{2}{*}{ drugs for joint or back pain } & Yes & 12.26 & 12.60 & 9.31 & 0.08 \\
\hline & & $(1958)$ & $(1754)$ & $(204)$ & \\
\hline \multirow[t]{3}{*}{ Hypertension or treated } & No & 55.18 & 55.05 & 56.37 & - \\
\hline & Yes & 44.82 & 44.95 & 43.63 & 0.96 \\
\hline & & $(1968)$ & $(1764)$ & $(204)$ & \\
\hline \multirow[t]{4}{*}{ Cholesterol (quartiles) } & Lowest & 50.87 & 50.60 & 53.23 & \\
\hline & Middle & 25.05 & 26.16 & 15.42 & \\
\hline & Highest & 24.08 & 23.24 & 31.34 & 0.02 \\
\hline & & $(1948)$ & $(1747)$ & $(201)$ & \\
\hline Diabetes & No & 91.02 & 91.01 & 91.09 & - \\
\hline \multirow[t]{2}{*}{ (glycemia $\geq 7 \mathrm{mmol} / \mathrm{L}$ or treated) } & Yes & 8.98 & 8.99 & 8.91 & 0.61 \\
\hline & & (1949) & $(1747)$ & (201) & \\
\hline Respiratory problem & No & 85.95 & 86.71 & 79.41 & - \\
\hline (dyspnea, asthma, bronchitis) & Yes & 14.05 & 13.29 & 20.59 & 0.006 \\
\hline
\end{tabular}




\begin{tabular}{|c|c|c|c|c|c|}
\hline & & \multicolumn{4}{|c|}{ Agoraphobia } \\
\hline & Class & $\begin{array}{c}\text { Total } \\
\% \\
(1968)\end{array}$ & $\begin{array}{c}\text { No } \\
\% \\
(1764)\end{array}$ & $\begin{array}{c}\text { Yes } \\
\% \\
(204)\end{array}$ & $p$-value \\
\hline Variable & & $(1957)$ & $(1753)$ & $(204)$ & \\
\hline \multirow[t]{3}{*}{ Stroke } & No & 97.29 & 97.20 & 98.03 & - \\
\hline & Yes & 2.71 & 2.80 & 1.97 & 0.90 \\
\hline & & (1953) & $(1750)$ & $(203)$ & \\
\hline \multirow{3}{*}{$\begin{array}{l}\text { Cardio- and cerebro-vascular } \\
\text { pathologies }\end{array}$} & No & 76.68 & 76.64 & 76.96 & - \\
\hline & Yes & 23.32 & 23.36 & 23.04 & 0.56 \\
\hline & & (1968) & $(1764)$ & $(204)$ & \\
\hline \multirow[t]{3}{*}{ Osteoporosis monitoring } & No & 81.46 & 82.41 & 73.27 & - \\
\hline & Yes & 18.54 & 17.59 & 26.73 & 0.17 \\
\hline & & (1947) & $(1745)$ & $(202)$ & \\
\hline \multirow{3}{*}{$\begin{array}{l}\text { Hospitalization for cancer } \\
\text { (past } 2 \text { years) }\end{array}$} & No & 98.58 & 98.70 & 97.55 & - \\
\hline & Yes & 1.42 & 1.30 & 2.45 & 0.10 \\
\hline & & (1968) & $(1764)$ & $(204)$ & \\
\hline \multirow{4}{*}{$\begin{array}{l}\text { Chronic pathologies } \\
\text { (number of) }\end{array}$} & 0 & 36.74 & 36.90 & 35.29 & \\
\hline & $1-2$ & 57.06 & 57.20 & 55.88 & \\
\hline & $3+$ & 6.20 & 5.90 & 8.82 & 0.11 \\
\hline & & (1968) & $(1764)$ & $(201)$ & \\
\hline \multirow[t]{3}{*}{ Benton score (lowest tercile) } & No & 61.48 & 62.21 & 55.17 & - \\
\hline & Yes & 38.52 & 37.79 & 44.83 & 0.22 \\
\hline & & $(1952)$ & (1749) & $(203)$ & \\
\hline Isaac score (lowest tercile) & No & 67.79 & 68.74 & 59.50 & - \\
\hline \multirow[t]{2}{*}{ (at $30 \mathrm{sec}$.) } & Yes & 32.21 & 31.26 & 40.50 & 0.013 \\
\hline & & (1937) & $(1737)$ & $(200)$ & \\
\hline \multirow[t]{3}{*}{ Hearing or visual deficiency } & No & 89.29 & 89.26 & 89.53 & - \\
\hline & Yes & 10.71 & 10.74 & 10.47 & 0.93 \\
\hline & & (1839) & $(1648)$ & $(191)$ & \\
\hline \multirow[t]{4}{*}{ Depressive symptomatology } & No & 69.78 & 71.39 & 55.94 & \\
\hline & Mild & 16.24 & 16.23 & 16.34 & \\
\hline & Severe & 13.98 & 12.39 & 27.72 & $<.0001$ \\
\hline & & $(1946)$ & $(1744)$ & $(202)$ & \\
\hline \multirow[t]{3}{*}{ History of major depression } & No & 74.82 & 75.87 & 65.67 & - \\
\hline & Yes & 25.18 & 24.13 & 34.33 & 0.02 \\
\hline & & (1950) & (1749) & $(201)$ & \\
\hline
\end{tabular}


Agoraphobia

\begin{tabular}{|c|c|c|c|c|c|}
\hline Variable & Class & $\begin{array}{c}\text { Total } \\
\% \\
(1968)\end{array}$ & $\begin{array}{c}\text { No } \\
\% \\
(1764)\end{array}$ & $\begin{array}{c}\text { Yes } \\
\% \\
(204)\end{array}$ & $p$-value \\
\hline \multirow[t]{3}{*}{ Spielberger Trait (highest tercile) } & No & 69.24 & 70.87 & 55.05 & - \\
\hline & Yes & 30.76 & 29.13 & 44.95 & 0.0005 \\
\hline & & $(1928)$ & $(1730)$ & $(198)$ & \\
\hline \multirow{3}{*}{$\begin{array}{l}\text { Confinement (bed, home or } \\
\text { neighbourhood) }\end{array}$} & No & 94.95 & 95.11 & 93.60 & - \\
\hline & Yes & 5.05 & 4.89 & 6.40 & 0.35 \\
\hline & & $(1962)$ & $(1759)$ & $(203)$ & \\
\hline \multirow[t]{3}{*}{ Mobility limitation } & No & 61.69 & 63.10 & 49.50 & - \\
\hline & Yes & 38.31 & 36.90 & 50.50 & 0.001 \\
\hline & & $(1929)$ & $(1729)$ & $(200)$ & \\
\hline \multirow[t]{3}{*}{ Incapacity for activities of daily } & No & 96.01 & 96.17 & 94.58 & - \\
\hline & Yes & 3.99 & 3.83 & 5.42 & 0.27 \\
\hline & & $(1954)$ & $(1751)$ & $(203)$ & \\
\hline \multirow[t]{3}{*}{ Falls (past months) } & No & 80.17 & 81.23 & 71.08 & - \\
\hline & Yes & 19.83 & 18.77 & 28.92 & 0.002 \\
\hline & & $(1962)$ & $(1758)$ & $(204)$ & \\
\hline \multirow[t]{3}{*}{ Serious life event (at least one) } & No & 41.08 & 40.85 & 43.23 & - \\
\hline & Yes & 58.92 & 59.15 & 56.77 & 0.43 \\
\hline & & $(1918)$ & $(1726)$ & $(192)$ & \\
\hline
\end{tabular}


Table 2. Incident cases of agoraphobia according to baseline variables: percentage of incident cases at each follow-up. Odds Ratios from a mixed regression model adjusted for age and time.

\begin{tabular}{|c|c|c|c|c|c|c|c|c|}
\hline \multirow[b]{2}{*}{ Variables at baseline } & & \multicolumn{2}{|c|}{$\begin{array}{c}\text { 2-year follow-up } \\
\qquad(N=1376)^{*}\end{array}$} & \multicolumn{2}{|c|}{$\begin{array}{l}\text { 4-year follow-up } \\
\qquad(N=1260)^{*}\end{array}$} & \multicolumn{3}{|c|}{$(N=1461)^{*}$} \\
\hline & & $\mathrm{N}$ & $\%$ & $N$ & $\%$ & OR & $95 \% \mathrm{Cl}$ & p-value \\
\hline \multirow[t]{2}{*}{ Sex } & Male & 623 & 5.94 & 563 & 5.33 & 1 & & \\
\hline & Female & 753 & 7.57 & 697 & 7.75 & 1.45 & $0.94-2.23$ & 0.092 \\
\hline \multirow[t]{3}{*}{ Education } & Low & 291 & 9.62 & 272 & 4.04 & 1 & & \\
\hline & Average & 381 & 6.30 & 350 & 10.0 & 0.82 & $0.45-1.47$ & 0.501 \\
\hline & High & 703 & 5.97 & 638 & 5.96 & 1.20 & $0.70-2.08$ & 0.504 \\
\hline \multirow[t]{3}{*}{ BMI $\left(\mathrm{kg} / \mathrm{m}^{2}\right)$} & $<25$ & 738 & 6.78 & 680 & 7.21 & 1 & & \\
\hline & $25-29$ & 522 & 7.85 & 478 & 5.86 & 0.99 & $0.64-1.55$ & 0.993 \\
\hline & $\geq 30$ & 108 & 1.85 & 96 & 6.25 & 0.46 & $0.18-1.19$ & 0.102 \\
\hline Regular use of anti-inflammatory & No & 1206 & 6.88 & 1097 & 6.93 & 1 & & \\
\hline drugs for joint or back pain & Yes & 161 & 5.59 & 155 & 4.52 & 0.69 & $0.34-1.39$ & 0.301 \\
\hline \multirow[t]{2}{*}{ Hypertension or treated } & No & 765 & 7.97 & 703 & 7.54 & 1 & & \\
\hline & Yes & 611 & 5.40 & 557 & 5.57 & 0.69 & $0.44-1.07$ & 0.100 \\
\hline \multirow[t]{3}{*}{ Cholesterol (quartiles) } & Lowest & 697 & 7.03 & 640 & 6.72 & 1 & & \\
\hline & Middle & 343 & 6.12 & 316 & 7.28 & 1.05 & $0.62-1.79$ & 0.844 \\
\hline & Highest & 327 & 7.34 & 297 & 6.06 & 1.02 & $0.55-1.88$ & 0.950 \\
\hline Diabetes & No & 1246 & 6.42 & 1144 & 6.82 & 1 & & \\
\hline (glycemia $\geq 7 \mathrm{mmol} / \mathrm{L}$ or treated) & Yes & 120 & 11.67 & 108 & 5.56 & 1.54 & $0.77-3.08$ & 0.223 \\
\hline Respiratory problem & No & 1221 & 6.55 & 1119 & 6.70 & 1 & & \\
\hline (dyspnea, asthma, bronchitis) & Yes & 150 & 9.33 & 133 & 6.77 & 1.50 & $0.78-2.85$ & 0.220 \\
\hline
\end{tabular}




\begin{tabular}{|c|c|c|c|c|c|c|c|c|}
\hline \multirow[b]{2}{*}{ Variables at baseline } & & \multicolumn{2}{|c|}{$\begin{array}{l}\text { 2-year follow-up } \\
\qquad(N=1376)^{*}\end{array}$} & \multicolumn{2}{|c|}{$\begin{array}{l}\text { 4-year follow-up } \\
\qquad(N=1260)^{*}\end{array}$} & \multicolumn{3}{|c|}{$(N=1461)^{*}$} \\
\hline & & $\mathrm{N}$ & $\%$ & $N$ & $\%$ & OR & $95 \% \mathrm{Cl}$ & $p$-value \\
\hline \multirow[t]{2}{*}{ Stroke } & No & 1332 & 6.61 & 1220 & 6.56 & 1 & & \\
\hline & Yes & 34 & 11.76 & 30 & 6.67 & 2.07 & $0.59-7.24$ & 0.252 \\
\hline \multirow[t]{2}{*}{ Cardio- and cerebro-vascular pathologies } & No & 1073 & 6.62 & 979 & 7.05 & 1 & & \\
\hline & Yes & 303 & 7.59 & 281 & 5.34 & 1.08 & $0.64-1.81$ & 0.767 \\
\hline \multirow[t]{2}{*}{ Osteoporosis monitoring } & No & 1132 & 7.16 & 1037 & 6.65 & 1 & & \\
\hline & Yes & 230 & 5.22 & 212 & 7.08 & 0.82 & $0.45-1.47$ & 0.504 \\
\hline Hospitalization for cancer & No & 1363 & 6.82 & 1246 & 6.66 & 1 & & \\
\hline (past 2 years) & Yes & 13 & 7.69 & 14 & 7.14 & 1.23 & $0.18-9.42$ & 0.797 \\
\hline \multirow[t]{3}{*}{ Chronic pathologies (number of) } & 0 & 525 & 6.67 & 477 & 6.71 & 1 & & \\
\hline & $1-2$ & 781 & 6.91 & 723 & 6.78 & 1.18 & $0.74-1.85$ & 0.481 \\
\hline & $3+$ & 70 & 7.14 & 60 & 5.00 & 1.15 & $0.41-3.25$ & 0.786 \\
\hline \multirow[t]{2}{*}{ Benton score (lowest tercile) } & No & 880 & 5.68 & 799 & 6.51 & 1 & & \\
\hline & Yes & 484 & 8.68 & 451 & 7.10 & 1.53 & $0.98-2.39$ & 0.058 \\
\hline Isaac score (lowest tercile) & No & 912 & 6.47 & 841 & 6.42 & 1 & & \\
\hline (at $30 \mathrm{sec}$.) & Yes & 440 & 7.73 & 398 & 7.04 & 1.26 & $0.81-1.98$ & 0.303 \\
\hline \multirow[t]{2}{*}{ Hearing or visual deficiency } & No & 1164 & 6.79 & 1074 & 6.89 & 1 & & \\
\hline & Yes & 123 & 8.13 & 109 & 3.67 & 0.94 & $0.44-2.01$ & 0.870 \\
\hline \multirow[t]{2}{*}{ Depressive symptomatology } & No & 1005 & 5.17 & 922 & 6.18 & 1 & & \\
\hline & Mild & 206 & 5.83 & 190 & 7.37 & 1.29 & $0.71-2.36$ & 0.408 \\
\hline
\end{tabular}




\begin{tabular}{|c|c|c|c|c|c|c|c|c|}
\hline \multirow[b]{2}{*}{ Variables at baseline } & & \multicolumn{2}{|c|}{$\begin{array}{l}\text { 2-year follow-up } \\
\qquad(N=1376)^{*}\end{array}$} & \multicolumn{2}{|c|}{$\begin{array}{c}\text { 4-year follow-up } \\
\qquad(N=1260)^{*}\end{array}$} & \multicolumn{3}{|c|}{$(N=1461)^{*}$} \\
\hline & & $\mathrm{N}$ & $\%$ & $N$ & $\%$ & OR & $95 \% \mathrm{Cl}$ & $p$-value \\
\hline & Severe & 148 & 17.57 & 133 & 9.02 & 3.81 & $2.08-6.97$ & $<0.0001$ \\
\hline \multirow[t]{2}{*}{ History of major depression } & No & 1066 & 6.10 & 981 & 6.01 & 1 & & \\
\hline & Yes & 299 & 9.03 & 269 & 8.92 & 1.70 & $1.05-2.74$ & 0.031 \\
\hline \multirow[t]{2}{*}{ Spielberger Trait (highest tercile) } & No & 967 & 5.27 & 896 & 5.47 & 1 & & \\
\hline & Yes & 387 & 10.59 & 347 & 10.09 & 2.48 & $1.58-3.90$ & $<0.0001$ \\
\hline Confinement (bed, home or & No & 1341 & 6.71 & 1218 & 6.81 & 1 & & \\
\hline Neighbourhood) & Yes & 30 & 10.00 & 38 & 2.63 & 1.11 & $0.27-4.64$ & 0.883 \\
\hline \multirow[t]{2}{*}{ Mobility limitation } & No & 5.55 & 901 & 5.83 & 823 & 1 & & \\
\hline & Yes & 8.74 & 446 & 8.29 & 410 & 2.33 & $1.43-3.81$ & 0.0007 \\
\hline Incapacity for activities of daily & No & 1333 & 6.68 & 1211 & 6.69 & 1 & & \\
\hline living & Yes & 32 & 12.50 & 37 & 5.41 & 1.82 & $0.53-6.19$ & 0.338 \\
\hline \multirow[t]{2}{*}{ Falls (past months) } & No & 1113 & 6.56 & 1026 & 7.12 & 1 & & \\
\hline & Yes & 258 & 7.75 & 230 & 4.78 & 0.98 & $0.56-1.7$ & 0.954 \\
\hline \multirow[t]{2}{*}{ Serious life event (at least one) } & No & 560 & 6.79 & 505 & 5.74 & 1 & & \\
\hline & Yes & 787 & 6.86 & 723 & 7.47 & 1.26 & $0.81-1.97$ & 0.302 \\
\hline
\end{tabular}

${ }^{*}$ maximum number of subjects. The minimum number of subjects used in the regression models is 1366 
